Año 11.

Frontera

Núm. 27
Revista de Investigación

Académica sin

ISSN: 2007-8870

\title{
http://revistainvestigacionacademicasinfrontera.com
}

Recibido el 23 de febrero de 2018. Dictaminado mediante arbitraje favorablemente 27 de mayo de 2018.

\section{Especificación de un modelo para el estudio de la percepción de los eventos de riesgo, la salud comunitaria, la calidad de vida y el bienestar subjetivo}

\begin{abstract}
Specification of a model for the study of the perception of risk events, community health, quality of life and subjective well-being
\end{abstract}

Juan José García-Ochoa ${ }^{1}$, Oscar Valdés-Ambrosio ${ }^{2}$, Cruz García-Lirios ${ }^{3}$

\section{Resumen}

Grosso modo, la salud comunitaria ha sido entendida como una variante de la salud pública, la cual históricamente ha sido definida desde un paradigma biomédico de atención a enfermedades, epidemias o pandemias centradas en la prevención, aunque los usuarios de los servicios de salud entienden que tal prevención consiste en la demanda de sus necesidades y la expedita atención. A partir de tal distinción el objetivo del presente trabajo es discutir los marcos teóricos, los modelos de atención y los estudios relativos a la salud comunitaria. Se realizó un trabajo documental con una selección intencional de fuentes indexadas a repositorios internacionales como Dialnet, Latindex, Redalyc y Scielo, considerando el lapso de publicación de 2006 a 2018 y la inclusión de conceptos tales como "salud comunitaria", “modelos de atención” y "estudios de autogestión”. Se advierten líneas de investigación complementarias de la identidad, factor esencial de la literatura consultada.

Palabras clave-Gobernanza, salud, repositorio, modelo, intervención

\footnotetext{
${ }^{1}$ USON, Facultad de Economía: jigarcia@navojoa.uson.mx

${ }^{2}$ UNAM, Facultad de Economía: oscarava@unam.mx

${ }^{3}$ UAEMEX: Facultad de Ciencias del Comportamiento: cgarcial213@profesor.uaemex.mx
} 
Año 11.

Frontera

Núm. 27
Revista de Investigación

Académica sin

ISSN: 2007-8870

\section{http://revistainvestigacionacademicasinfrontera.com}

\section{Abstract}

Grossly, community health has been understood as a variant of public health, which historically has been defined from a biomedical paradigm of attention to diseases, epidemics or pandemics focused on prevention, although users of health services they understand that such prevention consists of the demand of their needs and the expeditious attention. Based on this distinction, the objective of this paper is to discuss theoretical frameworks, models of care and studies related to community health. A documentary work was carried out with an intentional selection of sources indexed to international repositories such as Dialnet, Latindex, Redalyc and Scielo, considering the publication period from 2006 to 2018 and the inclusion of concepts such as "community health", "care models" and "self-management studies". Additional research lines of identity are seen, an essential factor of the literature consulted.

Keywords -Governance, health, repository, model, intervention

\section{Introducción}

El objetivo del presente trabajo es establecer los ejes y temas de discusión que inhiben la construcción de una agenda común en materia de salud comunitaria entre gobernantes y ciudadanos, así como las recomendaciones de superación de la gestión estatal y la autogestión comunitaria.

La salud comunitaria, para los fines del presente trabajo, alude a un sistema de gestión en el que la sociedad civil está excluida, aunque el nuevo institucionalismo posburocrático cada vez más atiende las demandas sociales. En este esquema de gestión y administración neoinstitucionalista, la salud comunitaria adquiere dimensiones que van desde la rectoría institucional hasta la autogestión civil, pero en ambos modelos uno u otro actor está 
Año 11.

Frontera

Núm. 27
Revista de Investigación

Académica sin

ISSN: 2007-8870

\section{http://revistainvestigacionacademicasinfrontera.com}

excluido de la agenda de salud, la toma de decisiones, las estrategias y las acciones de prevención o atención social (García, 2013).

A diferencia de los sistemas de gestión y autogestión, la salud comunitaria que se construye con el concurso de actores políticos y sociales no sólo genera una dinámica solidaria o cooperativa sino, además una evaluación de la calidad de sus procesos y productos, considerando objetivos, tareas y metas comunes (Bautista et al., 2016).

Sin embargo, la salud pública al ser concebida como resultado de un sistema de gestión estatal o autogestión civil, centró sus premisas básicas en los determinantes de la acción gubernamental o la acción colectiva sin asumir la integralidad de la cogestión. De este modo, los marcos teóricos que explican la administración de la salud pública centran su interés en la dinámica burocrática que supone la sincronía vertical entre líderes y talentos sin asumir que la comunicación y la motivación son resultado del clima de empatía y confianza, o bien, están vinculados a compromisos y habitus que distinguen a los profesionistas de la salud de otros gremios (Carreón et al., 2017).

Del mismo modo, los enfoques que explican la dinámica comunitaria de autogestión de la salud destacan la importancia de las relaciones de convivencia, el sentido de comunidad, el apego al lugar o la identidad local sin asumir que la evaluación de sus procesos generaría un mayor compromiso y responsabilidad ante eventos y problemáticas que pueden ser prevenidas con el concurso de especialistas en la materia y no sólo de los usos y costumbres regionales o cotidianos (García et al., 2013).

En ambos casos, la gestión estatal y la autogestión civil, la ausencia de una teoría comparativa e integrativa es evidente en los modelos de investigación o intervención, los cuales no sugieren una evaluación de los cambios antes y después de la implementación de estrategias, o bien, la ausencia de factores que supongan la construcción de un sistema 
Año 11.

Frontera

Núm. 27
Revista de Investigación

Académica sin

ISSN: 2007-8870

\section{http://revistainvestigacionacademicasinfrontera.com}

integral y que necesariamente transiten por la mediación, la conciliación o el arbitraje (García et al., 2017).

Pues bien, el nuevo institucionalismo orientado hacia la gobernanza supone la emergencia de actores sociales organizados que aglutinan las demandas sociales y establecen un diálogo con las autoridades, consiguiendo financiamientos o penetrando en la toma de decisiones o acciones de prevención, pero excluyendo a sectores que no tienen el nivel requerido de procesamiento de información para plantear sus demandas y establecer sus estrategias de intervención (Sandoval et al., 2017).

En tal sentido las propuestas de autogobierno: autogestión y autoadministración de los servicios de salud, centrados en medicina alternativa no excluyen del todo a especialistas y profesionistas de la salud, pero si destacan la importancia del respeto a sus usos y costumbres como parte de su identidad local, la cual es menester defender ante otras culturas o sistemas que cuestionan sus métodos de salud comunitaria (Valdés et al., 2017).

Sin embargo, las defunciones por enfermedades hidro-transmitidas de grupos vulnerados como los infantes no sólo es responsabilidad de la gestión estatal sino, además es responsabilidad de la autogestión civil ya que asumen una identidad de resistencia que supone conductas de riesgo, la cuales cobran la vida de mil millones de infantes cada año, aún y cuando cada familia sin acceso al agua potable destine cerca del $20 \%$ de sus ingresos, el incremento de muertes se intensifica en zonas periféricas a las urbes (García et al., 2016).

De este modo, la salud comunitaria está en una crisis de cogestión, principal estrategia de respuesta a las enfermedades hidro-transmitidas. Tal situación estriba en la exclusión de uno u otro actor en la prevención, aunque la ausencia de un marco teórico y conceptual en torno a la cogestión supone una falencia en el marco jurídico y en las propuestas de intervención (García et al., 2014). 
Año 11.

Frontera

Núm. 27
Revista de Investigación

Académica sin

ISSN: 2007-8870

\section{http://revistainvestigacionacademicasinfrontera.com}

Precisamente, la importancia de edificar una teoría de la salud comunitaria desde la visión de la cogestión estriba en el establecimiento de una agenda común que oriente a los actores políticos y sociales hacia la corresponsabilidad, aunque en principio se requiere superar la exclusión de uno u otro en la gestión estatal o la autogestión civil, así como su inclusión en las premisas que expliquen las diferencias y las similitudes de los sistemas de salud, orientando el reconocimiento de las estrategias y la superación de las deficiencias ya no sólo por la incompetencia sino por la exclusión de uno u otro actor (Carreón et al., 2016).

\section{Teoría de la Salud Comunitaria}

Los marcos teóricos que explican la salud comunitaria son: 1) teoría del nuevo institucionalismo, 2) teoría del establecimiento de la agenda y 3) teoría de la sociedad teledirigida.

La salud comunitaria, desde los tres enfoques, estriba en un sistema de gestión, autogestión y cogestión orientado a la prevención más que a la atención de enfermedades, accidentes, epidemias o pandemias, pero cada enfoque distingue entre el grado de confianza, compromiso, emprendimiento, innovación y satisfacción de cada susbsistema (García et al., 2015).

Precisamente, las diferencias entre gobernantes y ciudadanos reflejan los niveles de prevención como de atención frente a una problemática de salud en el orden comunitario. Cada aproximación ha explicado el proceso de asimetría en la toma de decisiones y las estrategias que redundan en la evaluación del desempeño o el autocuidado según el actor funcionario o usuario de los servicios de salud (Bautista et al., 2016).

De esa manera es que el nuevo institucionalismo procura la interlocución con los usuarios de los servicios de salud al momento de ajustar sus estrategias en la atención o la 
Año 11.

Frontera

Núm. 27
Revista de Investigación

Académica sin

ISSN: 2007-8870

\section{http://revistainvestigacionacademicasinfrontera.com}

prevención de enfermedades y accidentes comunes, pero desmarca a las autoridades de la agenda comunitaria en cuanto a usos y costumbres, o bien, tradiciones de medicina alternativa o procederes ancestrales (Carreón et al., 2017).

El nuevo institucionalismo es un esfuerzo para conciliar intereses estatales en la prevención de epidemias que si se ubican en la periferia de las ciudades no inhiban su dinámica, estableciendo cercos sanitarios, pero esencialmente una propaganda de autoresponsabilidad en la que las instituciones estatales se desmarcan de las conductas de riesgo y están prestas a la atención en la medida de sus posibilidades y capacidades (García, 2013).

Se trata del establecimiento de una agenda centrada en la rectoría del Estado como eje principal de la salud pública, aunque en el caso de la salud comunitaria, esa rectoría está simbolizada por las instituciones de servicios de salud. A diferencia del nuevo institucionalismo que destaca la importancia de atender las demandas sociales, el establecimiento de la agenda supone la emergencia de enfermedades que el Estado vincula a procesos electorales locales o federales (García, 2017).

En efecto, la politización de la salud comunitaria no sólo consiste en la difusión intensiva de inversiones en infraestructura, formación de profesionistas o calidad en la atención sino, esencialmente se observa en la ausencia de campañas de prevención que nulificarían la importancia de las políticas de salud y desmarcarían la responsabilidad en el individuo para abrir la discusión en torno a la construcción de un sistema de cogestión entre autoridades y usuarios, pero que el Estado prefiere establecer una agenda que sirva para sus intereses proselitistas y enmarque la salud en su rectoría omnipresente de la cual la sociedad es dependiente (Carreón et al., 2017). 
Año 11.

Frontera

Núm. 27
Revista de Investigación Académica sin

ISSN: 2007-8870

\section{http://revistainvestigacionacademicasinfrontera.com}

En esa lógica de la rectoría, la ciudadanía se auto-victimiza con la finalidad de demandar necesidades relacionadas con los subsidios y las compensaciones del Estado en cuanto a alimentación y campañas de donación. En esta fase, el nuevo institucionalismo embona con el establecimiento de una agenda centrada en la oferta de servicios de salud, pero vinculada a las próximas elecciones (Sandoval et al., 2017).

En este escenario de contienda electoral y agenda centrada en las enfermedades de los sectores más desprotegidos emergerán los efectos de la sociedad teledirigida en materia de salud pública en general y salud comunitaria en particular. Si los medios de comunicación intensifican la difusión de temas centrados en las necesidades de la sociedad civil vulnerada y si tal proceso se intensifica en las vísperas de elecciones locales o federales, entonces asistimos a un contexto en el que la salud es atribuida a la corrupción del gobierno en turno y a la urgencia de un cambio total y absoluto en lo político, social y comunitario vinculado a las enfermedades asociadas a la pobreza (Sandoval et al., 2017).

Es así como la sociedad teledirigida en materia de salud y elecciones supone el procesamiento de una agenda centrada en enfermedades comunes y atribuidas a la gestión del partido gobernante. En tal panorama, la salud comunitaria ya no consiste sólo en usos y costumbres locales ni depende únicamente de la inversión del Estado sino, además de la injerencia de los medios de comunicación en la difusión de enfermedades, la prevención de epidemias, la demanda de necesidades y la propaganda de gobernantes o candidatos (García et al., 2013).

El nuevo institucionalismo, el establecimiento de agenda y la sociedad teledirigida consisten en un procesamiento emocional de información que: 1) determina las enfermedades más comúnmente vinculadas a la pobreza como son las hidro-transmitidas en la agenda pública; 2) incide en las demandas sociales de atención a la salud más que de 
Año 11.

Frontera

Núm. 27
Revista de Investigación

Académica sin

ISSN: 2007-8870

\section{http://revistainvestigacionacademicasinfrontera.com}

prevención; 3) edifica una propaganda alusiva a la rectoría del Estado consistente en la edificación de hospitales, abastecimiento de medicamentos, atención médica expedita, afiliación a sectores vulnerados, otorgamiento de despensas o apoyos, todos y cada uno asociados al desempeño del partido gobernante, o bien, a la expectativa de un cambio de gobierno dedicado a la salud pública y comunitaria en un contexto electoral.

Por consiguiente, los modelos de salud comunitaria enfocan su interés en la atención de enfermedades al plantear contener la diseminación de una epidemia o la reducción a su mínima expresión y efecto. Se trata de un instrumento de gestión estatal que cada vez más está determinada por las estrategias y propagandas electorales de gobiernos en turno o partidos y candidatos aspirantes a gobernar la demarcación en donde prevalece una sociedad dependiente de los subsidios o condonaciones del Estado.

\section{Modelos de Salud Comunitaria}

Los modelos que explican la salud comunitaria son: 1) modelo de función exponencial, 2) modelo presa-predador, 3) modelo de propagación de enfermedades.

En principio, el modelo de función exponencial permitiría la anticipación de escenarios de alto contagio y riesgos a la salud en un grupo vulnerado. A partir de estos datos el Trabajador Social de una institución de salud básica promovería mediante imágenes el escenario de deterioro de la salud por la falta de higiene y ase personal diario entre los estudiantes (Ribeiro et al., 2007).

En el caso de la salud comunitaria, ambos modelos deterministas y estocásticos son esenciales para establecer una intervención centrada en el individuo, la familia, la institución y el entorno (Cheeran y Renjith, 2015). En el primer caso, la determinación de 
Año 11.

Frontera

Núm. 27
Revista de Investigación Académica sin

ISSN: 2007-8870

\section{http://revistainvestigacionacademicasinfrontera.com}

factores aleatorios es proclive en los casos individuales y aislados, el modelo aleatorio estocástico es fundamental para la anticipación de contagios en grupos y comunidades.

En el caso del modelo logístico, el profesional del Trabajo Social generaría un inventario a partir del cual las posibles víctimas de contaminación dermatológica tendrían que adoptar estilos de vida preventivos al reducir su contacto con los grupos en riesgo de contagio. De esta manera, los resultados logarítmicos permitirían tomar decisiones en contra o a favor de la separación de grupos infectados y grupos en riesgo, así como la reprogramación de sus actividades al interior del aula o fuera de ella (Walker, 2015).

Las redes de transmisión van más allá de una interacción aleatoria como la supone el modelo logístico (Montesinos y Hernández, 2007: p. 222). Por consiguiente, la inclusión de factores aleatorios y las interacciones entre los mismos es menester para anticipar escenarios factibles, pesimistas u optimistas.

Al ser las enfermedades potencializadas por la propagación mediante las asimetrías entre contagiado y víctima, el trabajo social escolar emerge como una respuesta a la diseminación de la equidad y la reducción de las asimetrías a su mínima expresión (Despard y Chowa, 2010).

Por su parte, el modelo de función presa-predador integraría los escenarios de contaminación exponencial probable con los efectos de esta contaminación en los grupos con mayor riesgo y en atención a los grupos de bajo riesgo. De esta manera, el modelo permitiría anticipar escenarios probables de una nueva contaminación dermatológica que sería confrontada con una difusión sistemática e intensiva de estrategias de colaboración en torno al cuidado del medio ambiente para la evitación de un nuevo brote (Way, 2013). 
Año 11.

Frontera

Núm. 27
Revista de Investigación Académica sin

ISSN: 2007-8870

\section{http://revistainvestigacionacademicasinfrontera.com}

El modelo predador-presa supone la interacción de factores aleatorios en los que las relaciones posibles establecen redes de propagación que, desde el Trabajo Social son esenciales para la promoción de estilos de vida libres de riesgo y estilos de autocuidado con base en los posibles contagios que una víctima potencial puede llegar a adquirir en un contexto determinado (García et al., 2017).

Si las redes de propagación advierten la dinámica potencial de una epidemia, los grafos explican la conformación de una propagación de enfermedad a partir de factores aleatorios e indeterminados (Montesinos y Hernández, 2007: p. 223). En tal sentido, ambos marcos teóricos y conceptuales permiten establecer áreas de oportunidad acordes a las capacidades difusoras del Trabajo Social en escenarios susceptibles al contagio y a la propagación de una epidemia.

Por último, el modelo de propagación de enfermedades, más ajustado a los requerimientos de cooperación y solidaridad para la gobernanza de la salud dermatológica, incluye no sólo a los grupos vulnerados por la enfermedad, sino además los escenarios de interacción futuros en los que nuevos brotes en otros grupos y el contagio de los primeros casos generaría un escenario de alto riesgo, pero con información suficiente para reducir sus efectos exponenciales y logísticos (Raudava, 2013).

A diferencia de los modelos exponencial, logístico y presa-predador, el factor de contagio o patrón de contacto, es el determinante de una propagación de contagio o proliferación de una epidemia (Montesinos y Hernández, 2007: p. 223). Precisamente, a partir de este factor la intervención del Trabajo Social adquiere una mayor relevancia ya que, si la propagación se establece mediante una interacción escolar, entonces la prevención resulta fundamental entre el Trabajador Social que coadyuva en las escuelas y el Trabajador Social que visita los escenarios domiciliares de familiares y amistadas propensas al contagio. 
Año 11.

Frontera

Núm. 27
Revista de Investigación

Académica sin

ISSN: 2007-8870

\section{http://revistainvestigacionacademicasinfrontera.com}

Los modelos de salud pública en general y de salud comunitaria en particular suponen que la relación entre gobernantes y gobernados está inconexa con las estrategias de prevención y autocuidado, las conductas de riesgo y los estilos de vida libres de enfermedades o accidentes. Además, suponen que la salud personal está desligada de la salud ocupacional, la cual ésta determinada por el acceso al servicio de salud pública (García et al., 2015).

En tal escenario, los modelos desmarcan al Estado de la corresponsabilidad que implica la promoción de estilos de ida saludables, libres de riesgos, enfermedades y accidentes, así como de una propensión al futuro que implica considerar a la salud como un activo común en las instituciones estatales y las organizaciones civiles.

\section{Estudios de Salud Comunitaria Percibida}

Los estudios de la salud comunitaria han establecido como factores preponderantes a las variables sociodemográficas, socioeconómicas y socioculturales como los determinantes de la calidad de vida, los servicios públicos y bienestar subjetivo, aunque las variables sociopolíticas han tenido un repunte dentro de los modelos predictivos (véase Tabla 1). 


\section{Revista de Investigación}

Año 11. Académica sin

Frontera

Núm. 27

\section{http://revistainvestigacionacademicasinfrontera.com}

ISSN: 2007-8870

\section{Tabla 1. Estudios de la salud comunitaria}

\begin{tabular}{|c|c|c|}
\hline Año & Autor & Resultados \\
\hline 1987 & Lara & $\begin{array}{l}\text { Demostró diferencias entre hombres y mujeres respecto al aborto inducido. El } 50 \text { por ciento de las mujeres y } \\
\text { el } 18 \text { por ciento de los hombres aceptaron la práctica abortiva inducida. También encontró diferencias } \\
\text { significativas con respecto al ámbito de trabajo. }\end{array}$ \\
\hline 1998 & Cabezas et al., & $\begin{array}{l}\text { Establecieron diferencias significativas entre las características sociodemográficas y el aborto inducido. } \\
\text { Respecto a la edad, encontraron diferencias entre mujeres menores de } 20 \text { años, entre } 20 \text { y } 25 \text { años y mayores } \\
\text { de } 25 \text { años con respecto al aborto inducido. En torno al nivel de estudios, establecieron diferencias } \\
\text { significativas entre quienes terminaron la primaria, secundaria, preparatoria y universidad con respecto al } \\
\text { aborto inducido. El estado civil también arrojó diferencias significativas entre casadas, solteras y en unión } \\
\text { libre con respecto al aborto provocado. Respecto a la ocupación, también se encontraron diferencias } \\
\text { significativas entre quienes son profesionistas, obreras, estudiantes o amas de casa en torno al aborto } \\
\text { practicado. Finalmente, la edad al momento de tener una relación sexual; menos de } 20 \text {, entre } 20 \text { y } 24 \text { y más de } \\
24 \text { años, también influyó en la práctica abortiva. Sólo en el tipo de raza; blanca, negra y mestiza no } \\
\text { observaron diferencias significativas. }\end{array}$ \\
\hline 1999 & $\begin{array}{l}\text { Castellanos, } \\
\text { García y } \\
\text { Mendieta }\end{array}$ & $\begin{array}{l}\text { Establecieron una asociación entre las necesidades detectadas del niño y su edad cronológica de desarrollo } \\
\text { sensoriomotor. En dicha relación, la intervención del tutor-terapeuta fue determinante. Dado que el } \\
\text { diagnóstico de las necesidades infantiles corresponde con la edad cronológica de desarrollo sensorial y motriz, } \\
\text { la función del especialista es fundamental para incidir en el desarrollo infantil. }\end{array}$ \\
\hline 1999 & Manza et al., & $\begin{array}{l}\text { Diseñaron un programa de estimulación temprana centrado en la familia. Advierten sobre la importancia de } \\
\text { incluir en la dinámica familiar el desempeño escolar como un efecto del cuidado de la salud física, emocional, } \\
\text { cognitiva y motora. El programa fue evaluado por jueces que le otorgaron validez de contenido. }\end{array}$ \\
\hline 1999 & $\begin{array}{l}\text { Sánchez, } \\
\text { Jiménez y } \\
\text { Merino }\end{array}$ & $\begin{array}{l}\text { Encontraron una actitud positiva hacia el aborto legal asistido y la práctica de aborto inducido o asistido por } \\
\text { personal médico de alguna institución o dependencia de salud. Establecieron diferencias significativas por } \\
\text { disciplinas de conocimiento con respecto a la práctica abortiva inducida. }\end{array}$ \\
\hline 2000 & Galvao & $\begin{array}{l}\text { Encontraron que } 75.4 \text { por ciento del personal médico recetó un método de anticoncepción de emergencia en la } \\
\text { muestra de especialistas encuestados. } 42.8 \text { recetaron la píldora de anticoncepción de emergencia en una } \\
\text { situación de riesgo. }\end{array}$ \\
\hline 2000 & García et al., & $\begin{array}{l}\text { Demostraron la disminución de la parálisis cerebral a partir de la estimulación inicial. Durante el tratamiento, } \\
\text { intervinieron tres áreas de desarrollo intelectual de suma importancia: audiovisual, rehabilitación física y } \\
\text { defecto logia congénita. Al término de la intervención, encontraron un incremento en el coeficiente de } \\
\text { desarrollo cognitivo conductual. }\end{array}$ \\
\hline 2000 & González & $\begin{array}{l}\text { Principalmente, el aborto inducido se lleva a cabo en lugares socioeconómicamente vulnerables, marginales o } \\
\text { excluidos en los que la población más joven o adolescente presenta una tasa superior en comparación con los }\end{array}$ \\
\hline
\end{tabular}


Año 11.

Frontera

Núm. 27
Revista de Investigación Académica sin

ISSN: 2007-8870

\section{http://revistainvestigacionacademicasinfrontera.com}

demás estratos económicos y poblaciones. Respecto a los conocimientos y las actitudes hacia la práctica abortiva inducida, se observa una tendencia conservadora respecto a la responsabilidad de practicarse un aborto. En este sentido, la situación económica y la presión conyugal o familiar son determinantes del aborto inducido.

\begin{tabular}{|c|c|c|}
\hline 2000 & Ramírez & $\begin{array}{l}\text { Encontró que el } 22 \text { por ciento de los hombres encuestados consideraron al aborto como un tema esencial de la } \\
\text { sexualidad. En contraste, el } 77 \text { por ciento de las mujeres identificaron al aborto como la principal } \\
\text { problemática en torno a su sexualidad. }\end{array}$ \\
\hline 2001 & Castro & $\begin{array}{l}\text { Encontraron que el } 8 \text { por ciento de la muestra encuestada no conocía los métodos de anticoncepción de } \\
\text { emergencia, } 84.9 \text { por ciento declararon tratamientos hormonales, } 69.7 \text { por ciento citaron como efecto } \\
\text { secundario los vómitos, el } 49.6 \text { por ciento declararon que si la anticoncepción la solicitaban menores de edad } \\
\text { deberían ir acompañados de algún familiar mayor. }\end{array}$ \\
\hline 2003 & $\begin{array}{l}\text { García, Lara y } \\
\text { Goldman }\end{array}$ & $\begin{array}{l}\text { Encontraron que el } 54 \text { por ciento de la muestra encuestada, considera que la opinión de las mujeres debe ser } \\
\text { escuchada en torno a la práctica abortiva inducida. El } 34 \text { por ciento cree que las mujeres abortan por } \\
\text { irresponsables, el } 56 \text { por ciento considera que las instituciones de salud deben ofrecer la asistencia de aborto } \\
\text { hasta el primer trimestre de gestación. Finalmente, el } 85 \text { por ciento considera que el aborto inducido está } \\
\text { justificado si la mujer corre un gran peligro de salud. }\end{array}$ \\
\hline 2004 & Barttlet et al., & $\begin{array}{l}\text { Encontraron que la depresión por cuestiones económicas, sociales o afectivas en las mamás de niños } \\
\text { migrantes con asma está asociada negativamente y significativamente al uso del inhalador y la ingesta del } \\
\text { medicamento contra la enfermedad. Si bien la relación entre depresión materna y adherencia al tratamiento } \\
\text { del asma no fue establecida directamente, sino sólo indirectamente a través de las creencias y actitudes, la } \\
\text { condición de exclusión fue un factor determinante de la salud ocupacional que se diseminó en el uso del } \\
\text { medicamento y dispositivo contra el asma. }\end{array}$ \\
\hline 2004 & Pando et al., & $\begin{array}{l}\text { Establecieron } 13 \text { factores de riesgo en torno al nacimiento de un grupo experimental antes y después de la } \\
\text { estimulación. Posteriormente, demostraron una disminución en los factores de riesgo del grupo experimental } \\
\text { en comparación al grupo control. Durante el lapso de la estimulación temprana de } 40 \text { semanas, el grupo } \\
\text { experimental alcanzo un mayor porcentaje de desarrollo cognitivo conductual en referencia al grupo control. }\end{array}$ \\
\hline 2005 & Campos et al., & $\begin{array}{l}\text { Establecieron tres etapas del estudio; diagnóstico, planificación e intervención para describir el efecto de la } \\
\text { ludo terapia en niños por parte de personal de enfermería y pediatría del Hospital General de San Rafael } \\
\text { Holojuela, Costa Rica. En la primera etapa, demostraron que los profesionales de la salud cuentan con } \\
\text { conocimientos básicos que por su grado de especialización han incidido disminuyendo los niveles de ansiedad } \\
\text { de los niños hospitalizados y sus familiares. }\end{array}$ \\
\hline 2005 & Davey et al., & $\begin{array}{l}\text { El acceso a la información sobre pruebas de detección del recién nacido fue la mayor demanda esgrimida en } \\
\text { referencia al banco de sangre como instrumento de información para la investigación del desarrollo infantil. }\end{array}$ \\
\hline 2006 & $\begin{array}{c}\text { Cerezo, } \\
\text { Trenado y Pons }\end{array}$ & $\begin{array}{l}\text { Establecieron dos conductas antecedentes infantiles; positiva y neutra, sensible y atenta en relación directa } \\
\text { con cuatro conductas consecuentes maternas; sensible atenta, sensible afectuosa, afectuosa intrusiva e } \\
\text { instrucción para observar las diferencias que fueron significativas entre dos grupos; bajo en coordinación y }\end{array}$ \\
\hline
\end{tabular}


Año 11.

Frontera

Núm. 27
Revista de Investigación Académica sin

ISSN: 2007-8870

\section{http://revistainvestigacionacademicasinfrontera.com}

alto en acoplamiento. En casi todas las combinaciones se demostraron diferencias significativas, sólo en el grupo de alto acoplamiento la respuesta intrusiva fue espuria en relación a la conducta antecedente infantil.

\begin{tabular}{|c|c|c|}
\hline 2006 & $\begin{array}{l}\text { Tejada y } \\
\text { Otalora }\end{array}$ & $\begin{array}{l}\text { Demostraron una asociación directa, positiva y significativa entre la estimulación cognitiva (madres que } \\
\text { estimulación a sus hijos e hijos que motivaron la participación materna) y el nivel de estudios en madres del } \\
\text { sector popular. La escolaridad obtenida en la muestra incluyó el nivel básico hasta medio superior. }\end{array}$ \\
\hline 2007 & $\begin{array}{l}\text { Enato, } \\
\text { Okhamafe y } \\
\text { Okpere }\end{array}$ & $\begin{array}{l}89 \% \text { de los encuestados identificaron a las picaduras de mosquito como el agente transmisor de la Malaria la } \\
\text { cual consideraron como el principal problema de salud durante los embarazos. En este sentido, los } \\
\text { entrevistadores desconocieron el uso de mosquiteros y la terapia preventiva intermitente. La relación entre } \\
\text { embarazo y paludismo es muy significativa como diagnóstico y prevención de salud. }\end{array}$ \\
\hline 2007 & González & $\begin{array}{l}\text { Estableció cinco áreas de la estimulación inicial; matemática, social, personal, cognitiva y motriz a partir de } \\
\text { las cuales definieron un sistema educativo estructurado orientado al desarrollo de los niños. Posteriormente, } \\
\text { demostró cinco efectos conductuales de la estimulación temprana: socialización, identidad, responsabilidad, } \\
\text { expresividad y responsabilidad. Sin embargo, algunos comportamientos de autocontrol e higiene no pudieron } \\
\text { ser instauradas. En este sentido, la estimulación inicial estuvo relacionada con el pensamiento divergente en } \\
\text { contraposición al pensamiento lógico -matemático. Cabe señalar que la estimulación temprana incentivó la } \\
\text { lecto-escritura a pesar de las limitaciones de los tutores-terapeutas en cuanto a conocimientos de } \\
\text { actualización de programas y estrategias de intervención. }\end{array}$ \\
\hline 2007 & Salazar & $\begin{array}{l}\text { Encontró que las actitudes hacia el aborto es neiliberal con un } 66.2 \text { por ciento, una actitud semiconserva dora } \\
\text { de } 26.2 \text { por ciento. En promedio, la muestra tuvo su primera experiencia sexual a los } 19 \text { años misma edad en } \\
\text { la que consideran que prefieren utilizar algún preservativo para evitar embarazos no deseados. }\end{array}$ \\
\hline 2007 & $\begin{array}{c}\text { Montesinos y } \\
\text { Hernández }\end{array}$ & $\begin{array}{l}\text { Ubican factores que integran relaciones estocásticas como el modelo logístico el cual no supone un control de } \\
\text { los factores que lo integran. }\end{array}$ \\
\hline 2008 & Kaptein et al., & $\begin{array}{l}\text { Llevaron a cabo un metaanálisis en torno a las percepciones de la enfermedad y encontraron que existe una } \\
\text { tendencia desfavorable al uso de dispositivos -inhaladores- para el tratamiento del asma, sugieren que las } \\
\text { intervenciones biomédicas y psicológicas al orientarse en el cambio de percepción de riesgo a utilidad de los } \\
\text { medicamentos y dispositivos, incrementarán la adherencia al tratamiento. }\end{array}$ \\
\hline 2008 & $\begin{array}{l}\text { Molina y } \\
\text { Bangero }\end{array}$ & $\begin{array}{l}\text { Consideraron seis áreas, dimensiones o factores de estimulación inicial; visual, auditiva, táctil, olfativa, } \\
\text { vestibular y sensorial correspondientes a las capacidades especiales de niños para diseñar un espacio de } \\
\text { estimulación. El diseño contempló la analogía de un espacio recreativo en el que los materiales serían los } \\
\text { principales estimuladores del desarrollo infantil. La propuesta también incluye la interrelación entre los } \\
\text { espacios tomando en cuenta la creatividad de los niños quienes podrían interactuar con otros niños de } \\
\text { capacidades especiales. }\end{array}$ \\
\hline 2008 & $\begin{array}{l}\text { Tapia, } \\
\text { Villaseñor y } \\
\text { Nuño }\end{array}$ & $\begin{array}{l}\text { 95\% declaró haber escuchado sobre la Anticoncepción de Emergencia, el } 80 \% \text { consideró a las píldoras como } \\
\text { un método de planificación, las mujeres tuvieron mayores razones para evitar un embarazo no deseado en } \\
\text { referencia a los hombres. Encontraron una actitud favorable hacia la anticoncepción de emergencia. El } 95 \text { por } \\
\text { ciento de la muestra declaró haber escuchado el método de anticoncepción de emergencia y el } 80 \text { por ciento lo }\end{array}$ \\
\hline
\end{tabular}




\section{http://revistainvestigacionacademicasinfrontera.com}

consideró un método adecuado.

2008 Tavara y Sacsa Establecieron diferencias significativas entre las características sociodemográficas y los conocimientos sobre el aborto inducido. Edad, estado civil y experiencia laboral fueron estadísticamente significativas en relación al conocimiento abortivo inducido. El legrado uterino, fue la técnica y el método abortivo mayormente mencionado en las entrevistas.

2009 Calderón y Encontraron una relación directa entre el consumo de licor entre las amistades de las mujeres que abortaban.

Alzamora El 65 por ciento de la muestra de mujeres abortivas tenía una amistad que consumía frecuentemente alcohol y el 41 por ciento de las mujeres casadas tenía una amistad que consumía frecuentemente alcohol. El 46\% de las parejas en situación de embarazó reconoció que su relación se tornó molesta luego de la prueba positiva de embarazo, el $15.5 \%$ se separó y sólo el $2.6 \%$ formalizó su relación.

$2009 \quad$ Chávez, Demostraron la actitud desfavorable hacia la práctica abortiva como consecuencia de la primera relación Pertzelova y sexual y el embarazo no deseado consecuente. Cerca del 26 por ciento de la muestra encuestada declaró usar Zapata un instrumento o dispositivo para prevenir el embarazo.

2009 Chávez, El 70\% recibió información de sus familiares, el 97\% conoció los preservativos, el 89\% tenía información

Petrzelova y sobre enfermedades de transmisión sexual, el 51\% consideró a las relaciones homosexuales como anormales,

Zapata el $41 \%$ estableció la mayoría de edad como ideal para iniciar una vida sexual, el 18\% manifestó que iniciaría sus relaciones sexuales después del matrimonio, pero el $18 \%$ tuvo su primer relación a los 16 años, el $25 \%$ reconoció haber sido presionado por sus amistadas a tener relaciones sexuales, el $31 \%$ declaró que sus padres verían mla el que tuviera relaciones sexuales, el $49 \%$ señaló que respetarían las reglas sobre sexualidad de sus padres, el 38\% consideró que podía quedar embarazada en su primera relación sexual, 18\% tuvo relaciones sexuales bajo los efectos del alcohol.

Demostró la asociación significativa de cuatro áreas de estimulación; motora, cognitiva, lecto-escritora y social. La primera dimensión se refiere a la estimulación y sus efectos sistemáticos kinestésicos en los que el niño adquiere habilidades y sobre todo, competencias o respuestas efectivas ante problemas determinados. El segundo factor se refiere al desarrollo de procesos psicológicos básicos tales como el lenguaje, la memoria y la percepción. En el tercer constructo, la inteligencia o coeficiente de intelectualidad fueron evidencia de las capacidades de comprensión de textos. Finalmente, en la última área, la estimulación es determinante de las habilidades sociales, comunicativas, discursivas e interpretativas.

\begin{tabular}{lcl}
\hline 2010 & Fernández & $\begin{array}{l}\text { Encontraron que el rango de edad en el que más se practican abortos es del 19 por ciento para la muestra de } \\
\text { entre } 26 \text { y } 30 \text { años. El } 16 \text { por ciento se ve obligado a abortar por la presión de la pareja, familia o su situación } \\
\end{array}$ \\
& & económica baja. \\
\hline $\mathbf{2 0 1 0}$ & Fernández et & Sólo en los casos en los que el aborto implica un peligro de muerte o trastorno postraumático, la decisión es \\
& al., & justificable \\
\hline $\mathbf{2 0 1 0}$ & Grimaldo y & Encontraron relaciones asociativas positivas significativas entre quienes tenían empleo y altos valores de \\
& Merino & permisividad, honestidad, legalidad y moralidad. Por el contrario, aquellos que no tenían trabajo manifestaban \\
& & bajos valores de permisividad, honestidad, legalidad y moralidad.
\end{tabular}

2010 Jara y Roda Establecieron la asociación significativa entre cinco fases de estimulación temprana. En la primera fase 
Año 11.

Frontera

Núm. 27
Revista de Investigación Académica sin

ISSN: 2007-8870

\section{http://revistainvestigacionacademicasinfrontera.com}

diagnóstica, llevaron a cabo entrevistas a los padres en torno a las capacidades de sus hijos. En la segunda fase planificaron una estructura curricular en la que la estimulación inicial sería incluida para incidir en el desarrollo integral del niño. En la tercera fase implementaron las habilidades adaptativas cuyos objetivos fueron aprender a conocer, hacer, vivir y ser. En la cuarta fase, diseñaron estrategias de mediación en la que la estimulación temprana de la institución sería complementada con estrategias de intervención familiares. En la quinta fase, llevaron a cabo estrategias de socialización e identificación familiar.

2010 Klaus, Piñeres El objetivo de las investigaciones fue establecer los puntos clave de su vida interior. En este sentido, las e Hincapie víctimas se consideran en un estado de "pecado" y no de explotación o indefensión. .

2010 Mariscal, Demostraron asociaciones directas y significativas entre los autores reportes parentales y las observaciones de Nieva y López habla de sus hijos. Establecieron dos tipos de habla: morfología irregular y morfología regular que correlacionaron positivamente con los intervalos de emisiones de palabras y protocolos de desarrollo gramatical. Ambas morfologías se incrementaban en la medida en que aumentaban las longitudes de habla. Es decir, el desarrollo del lenguaje está asociado con la estimulación de los padres hacia sus hijos.

2010 Martínez et al., Establecieron ocho etapas de la estimulación inicial para demostrar las diferencias significativas entre las técnicas de estimulación correspondientes a cada una de ellas. En la primera etapa de los cero a los tres meses, la estimulación fue más auditiva que visual en la que las gesticulaciones son importantes, pero lo son más las charlas, masajes, canciones, juegos y arrullos. En la segunda etapa de los tres a los seis meses, la estimulación mediante el cuidado, la compañía, la calma y la conversación fueron esenciales para la adquisición del lenguaje mediante el balbuceo. En la tercera etapa de los seis a los nueve meses, la estimulación auditiva tiende a ser desplazada por la estimulación kinestésica debido a que los ejercicios de torso y parietales desarrollaron sus destrezas motrices. En la cuarta etapa de los nueve a los doce meses, la estimulación sigue siendo auditiva y visual, pero en mayor medida es kinestésica ya que el balbuceo, el entrenamiento auditivo y visual, así como los juegos son esenciales para el desarrollo. En la quinta etapa de los 12 a los 18 meses el lenguaje se empieza a desarrollar con el refuerzo de conceptos en los que las palabras y los números tienen un efecto significativo en el aprendizaje de actividades cotidianas a través de la imitación. En la sexta etapa de los 18 a los 24 meses, la estimulación consistió en incentivar la narración con palabras trifásicas. En la séptima etapa de los 24 a los 30 meses, la estimulación auditiva verbal es efectuada con la lectura de libros, juegos infantiles y ejercicios nemotécnicos. Finalmente, en la octava etapa de los 30 a los 36 meses, la estimulación se llevó a cabo con la ayuda de películas y teléfonos en los que se ejercitaron los mensajes o contenidos auditivos, visuales y verbales.

2010 Obeichina et En contraste, la solicitud de interrupción del embarazo por irresponsabilidad o impericia anticonceptiva es al., estigmatizada. En este sentido, son inherentes estados depresivos derivados de la decisión o la práctica abortiva en mujeres con un compromiso suscrito

2010 Oduwole A medida que el compromiso con su pareja se prolonga, la elección de pareja es más evidente sobre las intenciones impersonales o unilaterales

2010 Sultan y Malik Al respecto, los estudios en torno a conocimientos y actitudes relativas al uso de dispositivos anticonceptivos del personal de salud son significativamente diferente a la opinión pública. Conocimientos insuficientes propiciados por una alta desinformación y actitudes negativas. Por ello se relacionaron con los conocimientos. 


\section{Revista de Investigación}

Año 11. Académica sin

Frontera

Núm. 27

ISSN: 2007-8870

\section{http://revistainvestigacionacademicasinfrontera.com}

\begin{tabular}{|c|c|c|}
\hline & & Sin embargo, la conciencia de contracepción a través del uso de píldoras es muy alta. \\
\hline 2011 & Aramayo & $\begin{array}{l}\text { Los abusos sexuales en la primera infancia incidieron en la sexualidad adulta. La réplica de las experiencias } \\
\text { sexuales del paso en el presente. La relación entre agresores y víctimas fue explicada a partir de las } \\
\text { experiencias sexuales del pasado. }\end{array}$ \\
\hline 2011 & $\begin{array}{l}\text { Castillo y } \\
\text { Chinchilla }\end{array}$ & $\begin{array}{l}\text { La mayoría de las víctimas son niñas o adolescentes entre los } 14 \text { y } 17 \text { años, alrededor del } 35 \% \text { han sido } \\
\text { abusadas sexualmente y } 40 \% \text { son madres. }\end{array}$ \\
\hline 2011 & $\begin{array}{l}\text { Desta y } \\
\text { Ragassa }\end{array}$ & $\begin{array}{l}\text { En la esfera privada, las investigaciones han encontrado representaciones ambivalentes: opinión a favor de la } \\
\text { despenalización del aborto y en contra de la práctica abortiva a través del inadecuado uso de anticonceptivos }\end{array}$ \\
\hline 2011 & $\begin{array}{l}\text { Escalona y } \\
\text { López }\end{array}$ & $\begin{array}{l}\text { Demostraron una asociación significativa entre la estimulación temprana y el desarrollo psicomotor durante } \\
\text { cuatro trimestres de intervención. Al principio, el } 83 \text { por ciento de las madres tenían un conocimiento } \\
\text { insuficiente del proceso estimativo. Al terminar la intervención sólo el cuatro por ciento tenían el mismo nivel } \\
\text { de conocimiento. }\end{array}$ \\
\hline 2011 & Fernández & $\begin{array}{l}\text { Estableció diferencias significativas antes y después de implementar un programa de musicoterapia en } \\
\text { mujeres violentadas en su hogar. A partir de organizar cantos individuales y grupales, estimuló a través de } \\
\text { sonidos la creatividad y la colaboración entre las participantes. Encontró niveles de estrés y ansiedad altos } \\
\text { antes de implementar el programa y una vez concluido realizó un nuevo diagnóstico y encontró niveles de } \\
\text { estrés y ansiedad más bajos en comparación a la primera medición. Respecto a la autoestima ésta aumento en } \\
\text { relación a la primera medición antes de implementarse la intervención. }\end{array}$ \\
\hline 2011 & Lanre & $\begin{array}{l}\text { Establecieron diferencias entre las actitudes hacia el aborto con respecto a la condición de la madre en } \\
\text { referencia al bebe. La legalización fue considerada como una medida de prevención ante el incremento de la } \\
\text { práctica abortiva clandestina. }\end{array}$ \\
\hline 2011 & $\begin{array}{l}\text { Mardones y } \\
\text { Guzmán }\end{array}$ & $\begin{array}{l}\text { La explotación sexual comercial está relacionada con el consumo de drogas, negligencia familiar, trastornos } \\
\text { psiquiátricos, deserción escolar y pobreza. La adherencia al tratamiento es menor a lo esperado ya que la } \\
\text { víctima reincide. }\end{array}$ \\
\hline 2011 & Olaitan & $\begin{array}{l}\text { Las diferencias existentes entre hombres y mujeres respecto al sexo consensuado, anticoncepción y aborto } \\
\text { inducido suponen al uso de dispositivos como instrumento de anticoncepción si las relaciones son ocasionales } \\
\text { e infrecuentes }\end{array}$ \\
\hline 2011 & Petracci & $\begin{array}{l}\text { En los casos opuestos, el coito interruptus es la práctica sexual más prevaleciente en hombres con un } \\
\text { compromiso afectivo significativo }\end{array}$ \\
\hline 2011 & Rivers & $\begin{array}{l}\text { Los estudios sobre la explotación sexual comercial tienden a centrar el problema como trata de blancas, } \\
\text { aunque justifican la idea de tráfico de personas, no sustentan las condiciones de explotación o esclavitud } \\
\text { sexual ya que las entrevistas con las que ejemplifican los casos las víctimas enfatizan su voluntad de } \\
\text { prostituirse para pagar sus deudas o apremios. }\end{array}$ \\
\hline 2011 & $\begin{array}{l}\text { Rodríguez y } \\
\text { Mayol }\end{array}$ & $\begin{array}{l}\text { Las decisiones de embarazo están sustentadas en criterios que determinan la indolencia o el apoyo hacia la } \\
\text { práctica abortiva }\end{array}$ \\
\hline
\end{tabular}


Año 11.

Frontera

Núm. 27
Revista de Investigación Académica sin

ISSN: 2007-8870

\section{http://revistainvestigacionacademicasinfrontera.com}

\begin{tabular}{|c|c|c|}
\hline 2011 & Serrano & $\begin{array}{l}\text { Demostró un incremento de los conocimientos sobre la prescripción abortiva de emergencia en relación con } \\
\text { los años de residencia médica. En la medida en que el tiempo de residencia se incrementaba, se observaba un } \\
\text { mayor porcentaje de conocimientos sobre la prescripción abortiva de emergencia. Hombres y mujeres evalúan } \\
\text { maternal o paternalmente a su pareja según sea el caso. Una evaluación positiva implica decisiones } \\
\text { compartidas. En cambio, una autoevaluación negativa determina una decisión delegada a la pareja. La } \\
\text { anticoncepción de emergencia fue el instrumento idóneo para prevenir embarazos no deseados, la frecuencia } \\
\text { de prescripción de la píldora aumentó el } 20 \% \text {, }\end{array}$ \\
\hline 2011 & $\begin{array}{l}\text { Silva, Ashton y } \\
\text { McNeil }\end{array}$ & $\begin{array}{l}\text { En general una relación percibida como externa a los intereses y propósitos personales incrementa las } \\
\text { posibilidades de delegar la decisión en la mujer }\end{array}$ \\
\hline 2011 & $\begin{array}{l}\text { Uribe y } \\
\text { Orcasita }\end{array}$ & $\begin{array}{l}76 \% \text { declaró haber recibido información sobre el VIH / SIDA, } 41 \% \text { utilizó la televisión para enterarse, } 32 \% \\
\text { reviso artículos de revistas, } 17.6 \% \text { utilizó folletos. Respecto al nivel de fobia } 85 \% \text { no le preocupa contraer el } \\
\text { VIH, pero el mismo porcentaje evita ver programas sobre el tema. } 82.4 \% \text { cree que es cero positivo, con el } \\
\text { mismo porcentaje declararon que podrían morir a causa del SIDA. }\end{array}$ \\
\hline 2011 & Whelan et al., & $\begin{array}{l}\text { Las píldoras de contracepción de emergencia (PCE) fueron desconocidas por su efectividad, administración, } \\
\text { función y acceso. Los más jóvenes consideraron que las PCE no previenen el embarazo, ignoran que pueden } \\
\text { adquirirla sin receta y tomarla después de } 12 \text { horas de la actividad sexual. }\end{array}$ \\
\hline 2012 & Becerra et al., & $\begin{array}{l}\text { 86.5\% manifestó un conocimiento aceptable sobre VIH, } 35.2 \% \text { señaló que podría infectarse por compartir } \\
\text { utensilios con portadores. Los conocimientos y las actitudes se asociaron positivamente. }\end{array}$ \\
\hline 2012 & $\begin{array}{l}\text { Davis, Shell \& } \\
\text { King }\end{array}$ & $\begin{array}{l}33 \% \text { de los técnicos atendían pacientes infectados por VIH, el } 86 \% \text { se sentía incómodo con la situación ya que } \\
\text { el } 44 \% \text { no deseaba promover antivirales. }\end{array}$ \\
\hline 2012 & Manavipour & $\begin{array}{l}\text { Demostró mediante un modelo estructural la convergencia de cuatro factores relacionados con el desarrollo } \\
\text { moral. Cada factor incluyó dos indicadores y los valores de ajuste del modelo fueron cercanos a la unidad con } \\
\text { cero residuales. }\end{array}$ \\
\hline 2012 & $\begin{array}{l}\text { Méndez, Rojas } \\
\text { y Moreno }\end{array}$ & Factores psicológicos, grupales y socioculturales explican los significados de la explotación sexual comercial. \\
\hline 2012 & Piaroza et al., & En tal sentido, el aborto está definido por el tipo de relación, duración, solides, expectativas y economía \\
\hline 2012 & Rice et al., & $\begin{array}{l}\text { Un incremento sustancial en la comunicación entre vendedores redujo significativamente la formación de } \\
\text { actitudes }\end{array}$ \\
\hline 2012 & $\begin{array}{l}\text { Selesho y } \\
\text { Modise }\end{array}$ & $\begin{array}{l}\text { Los estilos de enseñanza influyeron sobre las habilidades y las responsabilidades de los estudiantes. La } \\
\text { prevención del HIV / AIDS fue posible a partir de la implementación de habilidades sociales. }\end{array}$ \\
\hline 2012 & $\begin{array}{l}\text { Shelat, } \\
\text { Hihoriya y } \\
\text { Kumbar }\end{array}$ & $\begin{array}{l}\text { El proceso que va de impericia anticonceptiva hasta la práctica abortiva implica también una dimensión } \\
\text { pública en la que los hombres se manifiestan por la libertad de decisión de las mujeres a elegir o no } \\
\text { interrumpir su embarazo }\end{array}$ \\
\hline
\end{tabular}




\section{http://revistainvestigacionacademicasinfrontera.com}

\begin{tabular}{|c|c|c|}
\hline 2012 & Solat et al., & $\begin{array}{l}52.9 \% \text { estuvo consciente de los riesgos de contagio, } 39.9 \% \text { conocía las medidas de prevención, } 43.8 \% \text { nunca } \\
\text { había usado el condón, y } 17.2 \% \text { tenía conocimiento de su uso correcto }\end{array}$ \\
\hline 2012 & $\begin{array}{l}\text { Viveros y } \\
\text { Navia }\end{array}$ & $\begin{array}{l}\text { No obstante, la decisión de embarazo también está influida por la evaluación de la relación que al ser } \\
\text { calificada como poco sería incentiva la práctica abortiva }\end{array}$ \\
\hline 2013 & Abbasi et al., & $\begin{array}{l}97.9 \% \text { de los entrevistados declararon conocer el proceso de infección. } 94 \% \text { consideraron al virus como } \\
\text { mortal, } 81.6 \% \text { señalan que la infección es una tragedia personal, } 66 \% \text { señalaron que no existe vacuna alguna, }\end{array}$ \\
\hline 2013 & Cobos et al., & $\begin{array}{l}\text { Los grupos manifestaron un bajo nivel de conocimientos respecto a infecciones y enfermedades de } \\
\text { transmisión sexual, así como la percepción de estigmas en torno al VIH y sus portadores. A partir de tales } \\
\text { hallazgos se considera a la discriminación como la problemática central de las comunidades chontales. }\end{array}$ \\
\hline 2013 & Cosmas & $\begin{array}{l}\text { Los efectos secundarios fueron considerados como el principal efecto secundaría de las píldoras } \\
\text { contraceptivas. Las mujeres al seguir el consejo matriarcal de contracepción pueden ser inducidas a utilizar } \\
\text { otros métodos tradicionales y modernos. }\end{array}$ \\
\hline 2013 & García et al., & $\begin{array}{l}\text { La norma grupal incidió sobre la actitud hacia portadores de VIH }(\beta=.70) \text {. La relación indirecta entre sexo y } \\
\text { actitud a través de la norma }(\beta=-.47) \text {. }\end{array}$ \\
\hline 2013 & Giraldo & $\begin{array}{l}\text { Delimitar los conceptos de juventud y sexualidad a dimensiones comerciales soslaya factores relativos a la } \\
\text { expresividad. }\end{array}$ \\
\hline 2013 & Hernández & $\begin{array}{l}\text { Las mujeres migrantes son discriminadas por ser extranjeras y por su género, ambas segregaciones las hacen } \\
\text { vulnerables a la trata de personas. El traficante utiliza a la familia de las víctimas para establecer una relación } \\
\text { de dominio. }\end{array}$ \\
\hline 2013 & $\begin{array}{c}\text { Jouen y } \\
\text { Ziielinski }\end{array}$ & $\begin{array}{l}\text { El } 57 \% \text { de los turistas fueron europeos, el } 29 \% \text { declaró prevenir la explotación sexual debido a sus valores } \\
\text { sociales, el } 44 \% \text { utilizaría la denuncia anónima como instrumento de prevención. Sin embargo, el } 48 \% \text { no } \\
\text { conoce las normas punitivas de la explotación sexual. }\end{array}$ \\
\hline 2013 & Méndez & $\begin{array}{l}\text { El modo de reclutamiento fue una oferta laboral. A menudo un familiar o amigo cercano en quien confía la } \\
\text { víctima es utilizado para el reclutamiento. Las víctimas fueron trasladadas en transporte público. el temor a } \\
\text { represalias con la víctima o sus familiares inhibió el escape. El sistema judicial es percibido como corrupto y } \\
\text { colidido con los traficantes. La exclusión social fue asumida como un castigo de la comunidad ante la } \\
\text { situación de explotación sexual comercial. Las experiencias de explotación son asumidas como una } \\
\text { motivación para superarse. }\end{array}$ \\
\hline 2013 & Petro & $\begin{array}{l}\text { 23.3\% de los profesores declararon que los estudiantes están informados del impacto de las relaciones } \\
\text { sexuales en su vida académica, } 20 \% \text { señalan que los estudiantes son responsables de su sexualidad, } 33.3 \% \\
\text { manifestaron que la etapa sexual de los estudiantes supone una práctica temporal, } 53.3 \% \text { advirtieron que los } \\
\text { estudiantes ocupan su tiempo en relaciones sexuales más que en su vida académica, } 70 \% \text { consideró que la }\end{array}$ \\
\hline
\end{tabular}


Año 11.

Frontera

Núm. 27
Académica sin

ISSN: 2007-8870

\title{
http://revistainvestigacionacademicasinfrontera.com
}

educación sexual es determinante de los estilos de vida estudiantiles.

2014 Melton et al.,

Encontraron una relación espuria entre la alfabetización médica y la adherencia al tratamiento. Además, plantean que el efecto de la consulta médica sobre la adherencia se llevó a cabo a partir de tres diferencias; a) información deseada e información recibida; b) ensayos de aciertos frente a ensayos de error; c) expectativas de pacientes y expectativas de médicos.

\begin{abstract}
2015 Kardas, Lewell Evidenciaron las diferencias culturales entre pacientes de asma al demostrar que la ignorancia y la y Strzondala desesperanza inciden sobre la adherencia al tratamiento. De este modo, el sistema de atención social al estar diseñado para el servicio de una cultura de derechos a la salud excluye a las comunidades migrantes.

2017 García et al., Centraron su propuesta en la identidad sociopolítica como factor determinante de la gestión estatal, la autogestión civil y la cogestión parece obviar que la salud comunitaria está exenta de los efectos del cambio climático sobre la salud pública: la disponibilidad de recursos, las contingencias ambientales, los desastres naturales, las catástrofes ecológicas y las crisis atmosféricas.

2017 Carreón et al., Asumen a la identidad sociopolítica como capacidad de negociación, conciliación y responsabilidad compartida es suficiente para afrontar los riesgos y amenazas del entorno frente a las capacidades de las instituciones estatales y organizaciones civiles.

2017 Sandoval et al.,

Asumen que la resiliencia es sólo resultado de la identidad sociopolítica y además suficiente para establecer una agenda local acerca de las problemáticas locales y las oportunidades endógenas sin asumir que se trata más bien de un síntoma de desesperanza ante la imposibilidad de concertación entre los actores políticos y civiles.
\end{abstract}

Fuente: Elaboración propia

La salud comunitaria emerge cuando se incrementan los efectos del cambio climático sobre los climas locales. En ese sentido, subyacen epidemia porque se incrementa el calor potencial en zonas con bajo desarrollo humano; salud, educación y empleo, pero estas epidemias se diseminan en los demás sectores económicos por la dinámica de contagio. En tal sentido los modelos clásicos de salud pública ambiental adquieren relevancia con respecto al contagio de enfermedades; los modelos de Quetelet, Lotka, Volterra y McKendrick éste último idóneo para establecer modelos de intervención; prevención, 
Año 11.

Frontera

Núm. 27
Revista de Investigación

Académica sin

ISSN: 2007-8870

\section{http://revistainvestigacionacademicasinfrontera.com}

tratamiento y adhesión, pero acordes a la localidad en la promoción del autocuidado (Bautista et al., 2017).

Los estudios del Trabajo Social de la salud comunitaria muestran que la prevención es un factor de bajo costo con respecto al tratamiento de una enfermedad adquirida por una contaminación. En ese sentido, un modelo integral para el estudio de un brote de contaminación supone estrategias de intervención desde el Trabajo Social en instituciones de educación básica. El modelo de propagación Mckendrick ha sido identificado como el más completo, aunque la integración de otros modelos explica con mayor detalle la problemática de contagió y los escenarios futuros de tratamiento, contagio y prevención como son las estrategias de prevención y promoción de estilos de vida de autocuidado (García et al., 2016).

El Trabajo Social ha transitado de modelos de beneficencia, caridad y altruismo a modelos de diagnóstico, intervención, participación, gestión y corresponsabilidad acordes a las políticas de salud y los programas focalizados. En ese sentido, los modelos esgrimidos permiten la labor de promoción de la salud dermatológica y la difusión de innovaciones orientadas a la prevención de enfermedades en los grupos vulnerados (Abreu, 2009).

En el caso de una epidemia, la intervención del Trabajo Social resalta por sus capacidades de difusión del contagio, promoción de estilos de vida saludables libres de contaminación y estrategias de autocuidado. Se trata de dispositivos en los que el trabajador social genera información que contrarresta las creencias en torno a la propagación de enfermedades como es el caso de los parásitos (Reid, 2006).

Sin embargo, los aportes de los modelos de función exponencial, logístico, predador-presa y propagación de enfermedades pueden coadyuvar a edificar una intervención centrada en múltiples factores, con énfasis en el patrón de contagio y la adhesión al tratamiento, pero 
Año 11.

Frontera

Núm. 27
Revista de Investigación

Académica sin

ISSN: 2007-8870

\section{http://revistainvestigacionacademicasinfrontera.com}

sobre todo la propensión a la prevención mediante la influencia de grupos libres de riesgos y estilos de vida de autocuidado (Dominelli, 2012).

En tal sentido, el Trabajo Social comunitario, centrado en el perfil de líderes y su influencia en los grupos, es fundamental para la tarea de promoción de la salud y el autocuidado, pero sobre todo en la diseminación de valores y normas libres de riesgos (Duque, 2013).

No obstante, la contribución del Trabajo Social, un diálogo inter, multi y transdisciplinar con otras áreas y disciplinas de conocimiento es menester para ubicar la eficiencia, eficacia y efectividad del Trabajo Social en la prevención de enfermedades y la atención a casos de contagio o potencial propagación (Farinde y Gable, 2014).

Incluso, como disciplina de la salud, el Trabajo Social está llamado a establecer áreas de oportunidad y redes de colaboración con base en la formación profesional con competencias de negociación, mediación, conciliación y arbitraje (López y Chaparro, 2006)

A partir de los modelos exponencial, logístico, predador-presa y propagación de enfermedades se puede proponer un modelo integral en el que se especifican las relaciones de dependencia entre grupos contagiados, grupos potenciales al contagio, grupos de autocuidado, grupos potenciales de contagio y grupos que desarrollan nuevos estilos de prevención y autocuidado (García et al., 2017).

En este escenario, la intervención del trabajo social ya no sólo sería de promoción de la salud libre de contagio, sino además la difusión de estilos de vida de autocuidado y cooperación en la prevención de la enfermedad. Se trata de un proceso de salud colectiva en el que el objetivo es la evitación de un nuevo brote, o bien, la reducción a su mínima expresión (García, 2013). 
Año 11.

Frontera

Núm. 27
Revista de Investigación

Académica sin

ISSN: 2007-8870

\section{http://revistainvestigacionacademicasinfrontera.com}

La formalización de los modelos matemáticos para el estudio de la gobernanza de la salud dermatológica en grupos vulnerados supone una discusión en torno a los alcances y límites de los modelos con la finalidad de evidenciar su utilidad en la toma de decisiones, el establecimiento de programas de prevención y difusión de estilos de autocuidado (García et al., 2014).

Los estudios de la salud comunitaria muestran que, en el marco de la cogestión, la formación educativa y la formación profesional son fases consecutivas de compromiso y responsabilidad social con la problemática más que con la institución y con los usuarios del servicio de salud pública (Carreón et al., 2017).

Sin embargo, los límites de la salud comunitaria ocupacional en la adopción de modelos centrados en el equilibrio de demandas externas y recursos organizacionales estriban en las capacidades de autogestión más que en la conciliación de intereses entre autoridades y usuarios (García et al., 2017).

En tal sentido, la edificación de un modelo de salud comunitaria supone la contrastación de las necesidades locales con respecto a las políticas de protección civil. A partir de ambos modelos, es posible advertir que la salud comunitaria depende del estrés y los riesgos percibidos por los actores políticos y civiles (García et al., 2017).

La salud pública, en el marco de la gobernanza del desarrollo local, está indicada por el grado de resiliencia entre actores civiles y políticos con respecto al establecimiento de fondos que suponen una cogestión, pero que son determinados por las políticas de fomento empresarial y la salud ocupacional en la prevención de enfermedades y accidentes derivadas de actividades de riesgo (Sandoval et al., 2017) 
Año 11.

Frontera

Núm. 27
Revista de Investigación Académica sin

ISSN: 2007-8870

\section{http://revistainvestigacionacademicasinfrontera.com}

No obstante que la corresponsabilidad entre actores políticos y civiles es menester para alcanzar una salud comunitaria, en un plano simbólico, prevalecen representaciones de la juventud y representaciones de la vejez que definen la resiliencia y el afrontamiento de epidemias como un acto de identidad local más que como una construcción de necesidades y expectativas sociales (García, Carreón y Bustos, 2017).

Ello supone que la salud comunitaria incluye dos dimensiones relativas a la gobernanza y las tradiciones, normas y valores locales. Si bien, los ciudadanos edifican una representación de la salud con base en las diferencias de generaciones y sus capacidades de respuesta ante una epidemia, también es cierto que estas respuestas se aglomeran en torno a las expectativas de futuros gobernantes (García et al., 2017).

Si la salud pública y la salud comunitaria se desprenden del poder institucionalista estatal de gestión y administración del servicio de salud, entonces ante la corrupción que representan las autoridades, la sociedad civil ha construido una influencia que orienta conductas de riesgo y estilos de vida resilientes. En tal marco de gestión estatal y autogestión civil, la salud comunitaria es reducida a la injerencia de las políticas en la vida cotidiana y la evaluación civil en el desempeño de sus funcionarios (García et al., 2017).

Se trata de una influencia de autogestión de la salud comunitaria soportada socialmente por dos tipos de creencias relativas al abandono y al acompañamiento. En la medida en que los enfermos o potenciales víctimas de epidemias edifican creencias de soledad, sus expectativas de tratamiento se circunscriben a una atención especializada e inmediata, pero si más bien sus creencias giran en torno al acompañamiento, entonces sus expectativas y calidad de vida serán determinadas por el apoyo de familiares, amistades o compañeros de trabajo (Valdés et al., 2017). 
Año 11.

Frontera

Núm. 27
Revista de Investigación Académica sin

ISSN: 2007-8870

\section{http://revistainvestigacionacademicasinfrontera.com}

Empero, el factor esencial para el estudio de la autogestión comunitaria radica en la resistencia más que en la empatía o el compromiso como es el caso de los modelos de salud pública urbana. Se trata de una gestión compartida, pero centrada en la sociedad civil cooperativa y solidaria ante la tragedia que supone la pérdida de la salud colectiva por una epidemia (García et al., 2017).

Si la autogestión civil en materia de salud depende de sus relaciones de influencia más que de sus alianzas con el poder institucional estatal, entonces las políticas de salud parecen distanciarse de las estrategias centradas en el individuo como son los estilos de autocuidado o las conductas libres de riesgos, aunque en tal escenario la corresponsabilidad sería el punto de partida para alcanzar la salud comunitaria, luego de haber conseguido el bienestar subjetivo y la calidad de vida colectiva requeridas (García, 2017).

En pocas palabras los estudios de la salud comunitaria destacan las asimetrías entre gobernantes y gobernados con respecto a la prevención y la atención de los servicios públicos, aunque la proximidad del sistema de gestión estatal a las necesidades locales parece evidenciar una construcción social de las enfermedades en función de las edades, así como de los usos y costumbres. La salud comunitaria al estar indicada por la resiliencia comunitaria y la rectoría institucionalista difundido en los medios de comunicación implica un proceso emocional a partir del cual la información es procesada y aplicada a las acciones colectivas como gubernamentales. En función de estas afectividades se evalúan el desempeño de funcionarios, los programas de atención y las estrategias de prevención.

\section{Método}

¿Existen diferencias significativas entre los ejes y temas establecidos por la literatura en la agenda de los repositorios con respecto a las relaciones entre las variables reportadas en el estado de la cuestión? 
Año 11.

Frontera

Núm. 27
Revista de Investigación

Académica sin

ISSN: 2007-8870

\section{http://revistainvestigacionacademicasinfrontera.com}

Hipótesis nula: Existirán diferencias significativas entre los ejes y temas de la agenda con respecto a las relaciones entre las variables prevalecientes en el estado de la cuestión.

Hipótesis alterna: No existirán diferencias significativas entre los ejes y temas de la agenda de los repositorios con respecto a las relaciones entre las variables reportadas como hegemónicas en el estado de la cuestión.

Se llevó a cabo un estudio documental, transversal y exploratorio con una selección no probabilística de fuentes indexadas a repositorios nacionales como Latindex y Redalyc, considerando el año de publicación de 2006 a 2018, así como la inclusión de conceptos tales como: "salud comunitaria", "gestión estatal”, "autogestión civil”, "gobernanza" (véase Tabla 2).

Tabla 2. Descriptivos de la muestra

\begin{tabular}{llllllll}
\hline Sexo & $\%$ & Edad & $\%$ & Ingreso & $\%$ & Estado civil & $\%$ \\
\hline Masculino & 71,0 & $>29$ años & 58,9 & $<300$ USD & 21,8 & Soltero & 63,2 \\
\hline Femenino & 39,0 & $<29$ años & 52,1 & $>300$ USD & 89,2 & Otro & 47,8
\end{tabular}

Fuente: Elaborada con los datos del estudio

Se construyó una matriz de análisis de datos a partir de la técnica Delphi, la cual consiste en la comparación y la integración de información se llevó a cabo un análisis de contenido y agenda de datos en una matriz (Véase Tabla 3). 


\section{Revista de Investigación}

Año 11.

Académica sin

Frontera

ISSN: 2007-8870

Núm. 27

\section{http://revistainvestigacionacademicasinfrontera.com}

Tabla 3. Construcción de la matriz de análisis de contenido

\begin{tabular}{|c|c|c|c|c|}
\hline Factor & Concepto & Indicador & Medición & Interpretación \\
\hline $\begin{array}{l}\text { Propensión } \\
\text { a los riesgos }\end{array}$ & $\begin{array}{l}\text { Refiere a expectativas } \\
\text { desfavorables a la salud } \\
\text { comunitaria, la calidad } \\
\text { de vida y el bienestar } \\
\text { subjetivo. }\end{array}$ & $\begin{array}{l}\text { Datos, ideas e imágenes } \\
\text { relativas a estilos de } \\
\text { vida riesgosos }\end{array}$ & $\begin{array}{l}-1 \quad=\text { vinculado } \\
\text { negativamente con la } \\
\text { agenda, } 0=\text { desvinculado } \\
\text { de la agenda } y+1= \\
\text { vinculado con la agenda }\end{array}$ & $\begin{array}{l}\text { Un alto puntaje refiere a la } \\
\text { posibilidad de una gobernanza } \\
\text { entre los actores políticos y } \\
\text { sociales con respecto a la salud } \\
\text { comunitaria, la calidad de vida y } \\
\text { bienestar subjetivo. }\end{array}$ \\
\hline $\begin{array}{l}\text { Aversión a } \\
\text { los riesgos }\end{array}$ & $\begin{array}{l}\text { Refiere a expectativas } \\
\text { favorables hacia la salud } \\
\text { comunitaria, la calidad } \\
\text { de vida y el bienestar } \\
\text { subjetivo. }\end{array}$ & $\begin{array}{l}\text { Datos, ideas e imágenes } \\
\text { relativas a estilos de } \\
\text { autocuidado, adhesión } \\
\text { al tratamiento o } \\
\text { rehabilitación }\end{array}$ & $\begin{array}{l}-1 \quad=\text { vinculado } \\
\text { negativamente con la } \\
\text { agenda, } 0=\text { desvinculado } \\
\text { de la agenda y }+1= \\
\text { vinculado con la agenda }\end{array}$ & $\begin{array}{l}\text { Un alto puntaje refiere a la } \\
\text { posibilidad de una autogestión } \\
\text { social o gestión estatal de salud } \\
\text { comunitaria, calidad de vida y } \\
\text { bienestar subjetiva }\end{array}$ \\
\hline
\end{tabular}

Fuente: Elaboración propia

La información se procesó en el software de Análisis Cualitativo de Datos (QDA por su acrónimo en inglés versión 4,0), considerando las síntesis de memorandos y la comparación de los contenidos.

\section{Resultados}

La Figura 1 muestra la especificación del modelo con base en el análisis de contenido y la técnica Delphi. 
Año 11.

Frontera

Núm. 27
Revista de Investigación

Académica sin

ISSN: 2007-8870

\section{http://revistainvestigacionacademicasinfrontera.com}

Figura 1. Especificación del modelo de percepción de la salud comunitaria

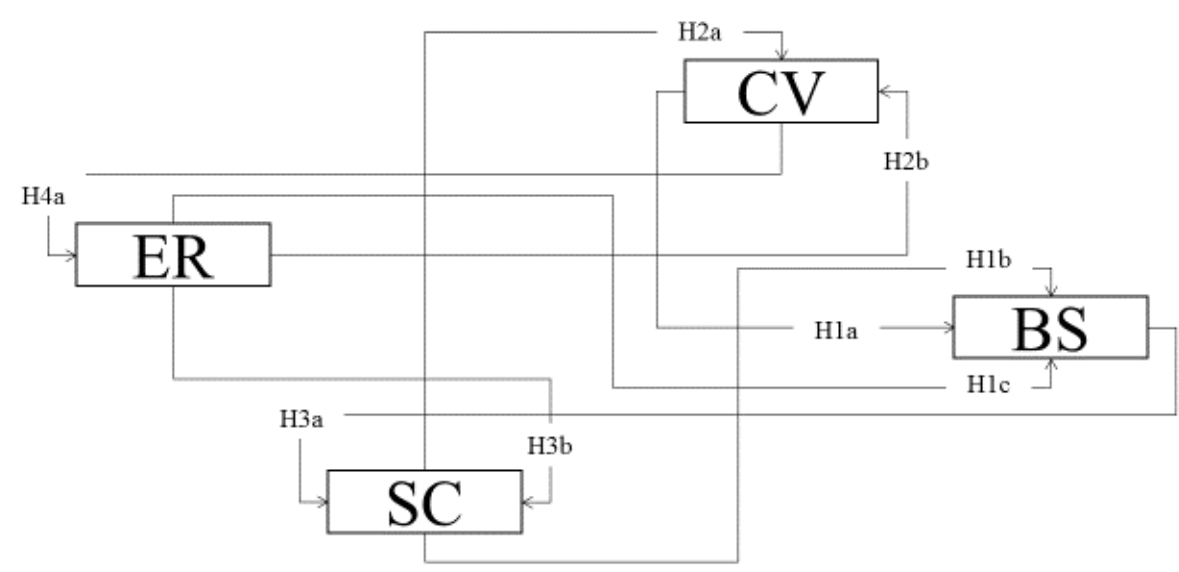

$\mathrm{BS}=$ Bienestar Subjetivo, $\mathrm{CV}=$ Calidad de Vida, $\mathrm{SC}=$ Salud Comunitaria, $\mathrm{ER}=$ Eventos de Riesgo.

Fuente: elaboración propia

El modelo incluye ocho trayectorias $[\mathrm{H} 1 \mathrm{a} ; \mathrm{H} 1 \mathrm{~b} ; \mathrm{H} 1 \mathrm{c} ; \mathrm{H} 2 \mathrm{a} ; \mathrm{H} 2 \mathrm{~b} ; \mathrm{H} 3 \mathrm{a} ; \mathrm{H} 3 \mathrm{~b} ; \mathrm{H} 4 \mathrm{a}$ 」 relativas a la aversión y la propensión del riesgo en cuanto a eventos de riesgo, salud comunitaria, calidad de vida y bienestar subjetivo todos en el plano de las representaciones sociales, específicamente desde las percepciones.

En la primera trayectoria que explica el bienestar subjetivo $\lceil\mathrm{H} 1 \mathrm{a} ; \mathrm{H} 1 \mathrm{~b} ; \mathrm{H} 1 \mathrm{c}\rfloor$ los eventos de riesgo como incendios, sequías, inundaciones, deslaves o sismos al ser considerados como efectos del cambio climático anticipan un deterioro de la salud comunitaria que se 
Año 11.

Frontera

Núm. 27
Revista de Investigación

Académica sin

ISSN: 2007-8870

\section{http://revistainvestigacionacademicasinfrontera.com}

reflejará en la reducción de la calidad de vida de sectores vulnerados y afectará su percepción de oportunidades de salud, educación y empleo.

Sin embargo, es probable que la información concerniente a los eventos de riesgo no siempre compagine con la calidad de los servicios públicos, indicador objetivo de la calidad de vida. En ese sentido, la escasez, el desabastecimiento, la insalubridad y la carestía del servicio de agua potable limitará el bienestar subjetivo indicado por el confort y la recreación hídrica.

En la segunda trayectoria $\{\mathrm{H} 2 \mathrm{a} ; \mathrm{H} 2 \mathrm{~b}\}$ que explica la calidad de vida a partir de la interrelación entre los eventos de riesgo y la salud comunitaria es posible observar; a) las sequías no sólo afectan los servicios hídricos sino, en interrelación con la salud comunitaria en su dimensión de insalubridad percibida reducen los satisfactores en torno a los recursos y servicios y hídricos.

Además, si el bienestar subjetivo estriba en el confort y la recreación hídrica, entonces la calidad de vida será reducida a su mínima expresión, aún y cuando los eventos de riesgo sean previstos y la salud comunitaria derive e un sistema eficaz.

En el tercer sendero $\lceil\mathrm{H} 3 \mathrm{a} ; \mathrm{H} 3 \mathrm{~b}\}$ la interrelación entre los eventos de riesgo y el bienestar subjetivo explican la salud comunitaria percibida ya que, las sequías, inundaciones, deslaves incendios o terremotos pueden minar la capacidad suministro del agua, pero si la sociedad civil asume una escasez generalizada el agua y por consiguiente un desabastecimiento anticipará una insalubridad y carestía del agua.

Por último, en la cuarta ruta $\lceil\mathrm{H} 4 \mathrm{a}\rfloor$ que explica los eventos de riesgo a partir de los satisfactores de la calidad, el confort y la recreación hídrica como temas de la agenda pública en materia de salud comunitaria explicarán la imagen de los huracanes, los 
Año 11.

Frontera

Núm. 27
Revista de Investigación

Académica sin

ISSN: 2007-8870

\section{http://revistainvestigacionacademicasinfrontera.com}

desbordes de ríos o la erosión de los bosques ya que, la sociedad civil informada contrastará su satisfactores con la opción latente de perderlos si se agravan los eventos de riesgo.

\section{Discusión}

El aporte del presente trabajo al estado de la cuestión radica en la discusión en torno a los eventos de riesgo, la salud comunitaria, la calidad de vida y el bienestar subjetivo pero la selección intencional de las fuentes informativas y la técnica de procesamiento limitan el debate a un contexto local más que regional o multilateral. Se recomienda extender la búsqueda de información en repositorios internacionales como Ebsco, Copernicus y Scopus con la finalidad de refinar el procesamiento a través de la minería de textos.

Pues bien, el aporte de la discusión centrada en una agenda relativa al Estado rector, así como en la ciudadanía resiliente estriba en a) la emergencia de la indefensión civil ante el poder institucionalista del servicio de salud y b) el advenimiento de conflictos entre autoridades y usuarios por la exclusión de uno u otro en la gestión estatal y la autogestión civil. En tal esquema es que será pertinente contrastar las premisas teóricas y modelos de la salud comunitaria como instrumento de poder estatal e influencia comunitaria, ambas enfocadas más en la atención que en la prevención, la cual implica la edificación de una cogestión.

En los tres planteamientos, la identidad sociopolítica ha explicado las asimetrías entre gobernantes y ciudadanos, pero no integra la gestión estatal con la autogestión comunitaria en situaciones de crisis ambientales, escasez de recursos y desabastecimiento de servicios públicos. Además, parecen obviar que las emociones sociopolíticas son suficientes para explicar y orientar la acción colectiva dirigida hacia el autogobierno, la autodefensa y la autogestión en materia de salud comunitaria y desarrollo local. 
Año 11.

Frontera

Núm. 27
Revista de Investigación

Académica sin

ISSN: 2007-8870

\section{http://revistainvestigacionacademicasinfrontera.com}

En contraste, la presente discusión pone de relieve la exclusión de los actores en torno a los sistemas de gestión estatal o autogestión civil. A partir de esta diferenciación será posible anticipar escenarios de cooperación y solidaridad en la prevención de enfermedades y accidentes que podrán extenderse a la erradicación de problemáticas como las epidemias o pandemias sin obviar que los efectos del cambio climático son emergentes.

Por lo tanto, es menester incluir en la discusión sobre salud comunitaria a los marcos teóricos, conceptuales y empíricos relativos a los efectos del cambio climático sobre la salud pública ambiental y la salud comunitaria con énfasis en la salud ocupacional, principal indicador de calidad de vida, bienestar subjetivo y representación de la salud.

\section{Conclusión}

El objetivo del presente trabajo al estado de la cuestión radica en la especificación de un modelo para el estudio de los eventos de riesgo, la salud comunitaria, la calidad de vida y el bienestar subjetivo, aunque el tipo de estudio, muestreo y análisis limitan la especificación al escenario de la investigación, sugiriendo el contraste local y regional para la confiabilidad y la validez del instrumento que mida las relaciones entre las variables del modelo.

\section{Referencias}

García, C., Carreón, J., Hernández, J. y Bustos, J. M. (2013). Actitud de trabajadoras sociales hacia portadores del Virus de Inmunodeficiencia Humana en centros de salud comunitaria. Salud \& Sociedad, 4 (1), 60-68

García, C. (2013) creencias en torno al aborto inducido en un hospital público. Salud Pública, 22, 14-19 
Año 11.

Frontera

Núm. 27
Revista de Investigación

Académica sin

ISSN: 2007-8870

\section{http://revistainvestigacionacademicasinfrontera.com}

García, C., Carreón, J., Hernández, J. y Morales, M. L. (2014). Contraste de un modelo de compromiso laboral en una institución de salud pública. Acta Universitaria, 24 (1), 48-59

García, C., Carreón, J., Bustos, J. M., Hernández, J. y Salinas, R. (2015). Especificación de un modelo de comunicación de riesgos ambientales ante el cambio climático. Entreciencias, 3 (6), 71-90

Carreón, J., Bustos, J. M., Hernández, J. y García, C. (2016). Confiabilidad y validez de un instrumento que mide la actitud hacia grupos cercanos a portadores de VIH / SIDA. Eureka, 12 (2), 218-230

García, C., Carreón, J., Sandoval, F. J., Bustos, J. M. y Aguilar, J. A. (2016). Estructura de la cultura laboral en una institución de salud pública. Arequipa, 6 (1), 291-304

Carreón, J., Bautista, M., García, C., Hernández, G., Sandoval, F. J., Pérez, G. y Valdés, O. (2016). Confiabilidad y validez de un instrumento que mide percepciones de salud ocupacional en migrantes de Huehuetoca, Estado de México. Obets, 11 (2), 569-581

Bautista, M., Delgado, M. A., García, C., Valdés, O., Hernández, G., Castro, A. y Trujillo, K. V. (2016). Contrastación de un modelo de cultura organizacional en centros de salud comunitaria ante la difusión informativa del VIH / SIDA desde el Trabajo Social. Enseñanza e Investigación en Psicología, 21 (3), 248-255

Abreu, M. A. (2009). El trabajo social sanitario en la atención primaria de salud. Enfermería, 3 (2), 70-79 
Año 11.

Frontera

Núm. 27
Revista de Investigación

Académica sin

ISSN: 2007-8870

\section{http://revistainvestigacionacademicasinfrontera.com}

Carreón, J., Hernández, J., Bustos, J. M. y García, C. (2017). Confiabilidad y validez de un instrumento que mide el compromiso de trabajadoras sociales en instituciones de asistencia sanitaria. Encrucijada, 26, 69-86

Cheeran, M. y Renjith, G. (2015). Scope of social work profession in industrial establishment. International Journal of Advances Research in Management and Social Sciences, 4 (8), 315-326

Despard, M. y Chowa, G. (2010). Social workers' interest in building individuals' financial capabilities. Journal Financial Therapy, 1 (1), 23-41

Dominelli, L. (2012). Antidepresive social work theory and practice. Trabajo Social, 14, 2013-215

Farinde, A. y Gable, K. (2014). Interprofesional practice approach between social work and pharmacy. International Journal Social Work, 1 (1), 70-77

García, C. (2017). Política de salud comunitaria y la adhesión al tratamiento del cáncer cervical en una comunidad del centro de México. Epsys, 21, 1-6

García, C., Carreón, J. y Bustos, J. M: (2017). La salud ocupacional de unos adultos mayores en un contexto electoral de una localidad del centro de México. Doxa, 7 (12), 36-49

García, C., Carreón, J. y Hernández, J. (2017). Límites de los modelos de salud ocupacional. Estudio de adhesión al tratamiento del asma en trabajadore3s migrantes adultos mayores del Estado de México. Visión Gerencial, 16 (1), 103-118 
Año 11.

Frontera

Núm. 27
Revista de Investigación

Académica sin

ISSN: 2007-8870

\section{http://revistainvestigacionacademicasinfrontera.com}

García, C., Carreón, J., Hernández, J. y Bustos, J. M. (2017). Poder institucionalista e influencia civil en la mediación del trabajo social ante políticas y necesidades sociales. Crítica \& Resistencia, 4, 250-264

García, C., Carreón, J., Hernández, J., Bustos, J. M. y Quintero, M. L. (2017). Expected and perceived governance in a social rehabilitation center from México City. International Journal of Advances in Social Science and Humanities, 5 (5), 6-13

García, C., Juárez, M., Sandoval, F.. R. y Bustos, J. M. (2017). Una aproximación psicológica a la complejidad ambiental: Especificación de un modelo de estrés y resiliencia comunitaria. Comunitaria, 14, 75-95

García, C., Sandoval, F. R., Rivera, B. L. y Limón, G. A. (2017). Complejización de un modelo para el estudio de la resiliencia ambiental. Investigación Académica Sin Frontera, 10 (25), 1-13

López, E. y Chaparro, M. (2006). Competencias laborales del trabajador social vista desde el mercado laboral. Tabula Rasa, 5, 261-293

Montesinos, O. A. y Hernández, C. M. (2007). Modelos matemáticos para enfermedades infecciosas. Salud Pública de México, 49 (3), 218-223

Raudava, C. (2013). The impacts for developing the profession of social work in the postcomunist context. European Scientific Journal, 9 (20), 12-30

Reid, P. (2006). The purpose of a school of social work. An American perspective. Social Work Education, 25 (5), 461-484 
Año 11.

Frontera

Núm. 27
Revista de Investigación

Académica sin

ISSN: 2007-8870

\section{http://revistainvestigacionacademicasinfrontera.com}

Ribeiro, M., López, R. y Mancinas, S. (2007). Trabajo social y política social en México. Revista Internacional de Ciencias Sociales y Humanidades, 17 (2), 175-200

Sandoval, F. R., Carreón, J., García, C., Quintero, J. M. y Bustos, J. M. (2017). Modelo de los determinantes de la percepción de resiliencia a partir del riesgo y estrés percibidos en relación con la gobernanza de la protección civil. Invurnus, 12 (1), 30-35

Valdés, O., Vilchis, F. J, Bautista, M., García, C. y Castro, A. (2017). Adhesión al tratamiento de insuficiencia renal crónica en una comunidad del Estado de México. Margen, 84, 1-8

Walker, S. (2015). The pendulum swings back: relation based social work in England then and now. Journal of International Scientific Publications, 13, 49-56

Way, M. (2013). Feminist theory, lesbian parents and social work. Sincronía, 17 (63), 1-20 